\title{
Paolo Tamassia, Politiche della scrittura. Sartre nel dibattito francese del Novecento su letteratura e politica
}

\section{Emanuele Kanceff}

\section{(2) OpenEdition}

1 Journals

\section{Edizione digitale}

URL: https://journals.openedition.org/studifrancesi/41197

DOI: 10.4000/studifrancesi.41197

ISSN: 2421-5856

\section{Editore}

Rosenberg \& Sellier

\section{Edizione cartacea}

Data di pubblicazione: 1 juillet 2004

Paginazione: 221

ISSN: 0039-2944

\section{Notizia bibliografica digitale}

Emanuele Kanceff, «Paolo Tamassia, Politiche della scrittura. Sartre nel dibattito francese del Novecento su letteratura e politica», Studi Francesi [Online], 142 (XLVIII | I) | 2004, online dal 30 novembre 2015, consultato il 09 septembre 2021. URL: http://journals.openedition.org/studifrancesi/41197; DOI: https://doi.org/10.4000/studifrancesi.41197

\section{Questo documento è stato generato automaticamente il 9 septembre 2021.}

\section{(c) (1)}

Studi Francesi è distribuita con Licenza Creative Commons Attribuzione - Non commerciale - Non opere derivate 4.0 Internazionale. 


\title{
Paolo Tamassia, Politiche della scrittura. Sartre nel dibattito francese del Novecento su letteratura e politica
}

\author{
Emanuele Kanceff
}

\section{NOTIZIA}

PAOLO TAMASSIA, Politiche della scrittura. Sartre nel dibattito francese del Novecento su letteratura e politica. Milano, FRANCOANGELI, 2001, pp. 186.

1 Nonostante, o proprio a causa della copiosissima letteratura critica esistente sul rapporto tra politica e letteratura nel Novecento e dell'altrettanto copiosissima produzione su Sartre e il suo impegno politico, una messa a punto come quella che ci offre Paolo Tamassia era necessaria ed è benvenuta. Sostanzialmente, l'autore ci pone dapprima di fronte ad un carosello di scrittori che hanno costituito altrettante tappe essenziali di riflessione sull'argomento, per venire poi più specificamente al pensiero sartriano e alla sua concezione di littérature engagée. Infine, Tamassia analizza la posizione di Sartre "oltre la littérature engagée», la sua revisione dello statuto della poesia, il potere eversivo dell'immaginario, l'autonomia e la materialità dell'oggetto estetico. Un saggio, insomma, lucido e brillante, che si legge con piacere. 